\title{
The p75 neurotrophin receptor is expressed by adult mouse dentate progenitor cells and regulates neuronal and non-neuronal cell genesis
}

\author{
Ramon O Bernabeu ${ }^{1,2}$, Frank M Longo ${ }^{3^{*}}$
}

\begin{abstract}
Background: The ability to regulate neurogenesis in the adult dentate gyrus will require further identification and characterization of the receptors regulating this process. In vitro and in vivo studies have demonstrated that neurotrophins and the p75 neurotrophin receptor $\left(p 75^{\text {NTR }}\right.$ ) can promote neurogenesis; therefore we tested the hypothesis that $p 75^{\text {NTR }}$ is expressed by adult dentate gyrus progenitor cells and is required for their proliferation and differentiation.

Results: In a first series of studies focusing on proliferation, mice received a single BrdU injection and were sacrificed 2, 10 and 48 hours later. Proliferating, BrdU-positive cells were found to express $\mathrm{p} 75^{\mathrm{NTR}}$. In a second series of studies, BrdU was administered by six daily injections and mice were sacrificed 1 day later. Dentate gyrus sections demonstrated a large proportion of BrdU/p $75^{\text {NTR }}$ co-expressing cells expressing either the NeuN neuronal or GFAP glial marker, indicating that $\mathrm{p} 75^{\mathrm{NTR}}$ expression persists at least until early stages of maturation. In $\mathrm{p} 75^{\mathrm{NTR}}$ $(-/-)$ mice, there was a 59\% decrease in the number of BrdU-positive cells, with decreases in the number of BrdU cells co-labeled with NeuN, GFAP or neither marker of 35\%,60\% and $64 \%$, respectively.

Conclusions: These findings demonstrate that $\mathrm{p} 75^{\mathrm{NTR}}$ is expressed by adult dentate progenitor cells and point to $\mathrm{p} 75^{\mathrm{NTR}}$ as an important receptor promoting the proliferation and/or early maturation of not only neural, but also glial and other cell types.
\end{abstract}

\section{Background}

Neurons and astrocytes in the dentate gyrus of the hippocampus continue to be replaced throughout adult life in several species including humans [1-6]. Given the therapeutic implications of promoting neurogenesis in the dentate gyrus $[7,8]$, it is becoming increasingly important to identify the mechanisms involved in the early stages of adult stem cell proliferation and differentiation. Receptors amendable to small molecule therapeutic targeting are of particular interest.

Several lines of evidence raise the possibility that neurotrophins and their receptors might be capable of regulating dentate progenitor proliferation and/or differentiation. Mature neurotrophins interact with two types of receptors: the Trk tyrosine kinase receptors

\footnotetext{
* Correspondence: longo@stanford.edu

${ }^{3}$ Department of Neurology and Neurological Sciences, Stanford University, Palo Alto, CA, 94035, USA

Full list of author information is available at the end of the article
}

(TrkA, TrkB, and TrkC) and the p75 neurotrophin receptor $\left(\mathrm{p} 75^{\mathrm{NTR}}\right)$ [9]. $\mathrm{p} 75^{\mathrm{NTR}}$ receptors promote neuronal death or survival depending on the cellular context and the actions of a complex array of intracellular adaptors [10-12]. In in vitro studies, p $75^{\mathrm{NTR}}$-linked signaling has also been found to regulate cell cycle progression and/or cellular maturation of the following cell types: human oral keratinocyte stem/progenitor cells [13]; myoblasts [14], PC12 cells [15]; neuroblasts [16], embryonic striatal progenitors [17]; embryonic forebrain neurospheres [18]; and subventricular zone cells [19]. Mouse embryonic stem cells have been shown to express $\mathrm{p} 75^{\mathrm{NTR}}$ and NGFinduced proliferation of these cells can be inhibited by a p $75^{\text {NTR }}$ blocking antibody [20].

The question of whether $\mathrm{p} 75^{\mathrm{NTR}}$ regulates proliferation or maturation of neural progenitors in vivo has been examined in the context of the subventricular zone (SVZ), olfactory bulb and subgranular zone (SGZ) of the dentate gyrus. Giuliani et al [21] demonstrated that

\section{Ciomed Central}


p $75^{\text {NTR }}$ is expressed by a large population of dividing cells in the adult SVZ while TrkA and TrkB expression was not detected. In NCAM-/- mice, Gascon et al. [22] found increased $\mathrm{p} 75^{\mathrm{NTR}}$ expression in the rostral migratory stream-olfactory bulb that was associated with early maturation and increased levels of death in the progenitor population. Young et al. [23] also found that $\mathrm{p} 75^{\mathrm{NTR}}$ is expressed by SVZ cells in adult mice. In p75 7 NR-/mice, they observed a $25-45 \%$ reduction in the number of SVZ PSA-NCAM-positive neuroblasts and a significant reduction in olfactory bulb weight. In neurospheres derived from these mice, in which expression of TrkA or TrkB receptors was not detected, BDNF- and NGFinduced neurogenesis was found to be mediated entirely by $\mathrm{p} 75^{\mathrm{NTR}}$, further pointing to a role for $\mathrm{p} 75^{\mathrm{NTR}}$ in regulating SVZ neurogenesis. A recent study assessed dentate gyrus neurogenesis in $\mathrm{p} 75^{\mathrm{NTR}-/-}$ mice and found a $50 \%$ decrease in the number of BrdU-positive cells using a $36 \mathrm{~h}$ BrdU labeling protocol followed by cell counts at the two week time point [24]. At the six-week time point, there was no difference in wildtype versus mutant mice in the number of cells co-labeled by BrdU and the neuronal marker NeuN. These observations raised the possibility that $\mathrm{p} 75^{\mathrm{NTR}}$ might be required for dentate progenitor proliferation. However, the key questions of whether $\mathrm{p} 75^{\mathrm{NTR}}$ is expressed by proliferating progenitors, whether $\mathrm{p} 75^{\mathrm{NTR}}$ is expressed by non-neuronal cells and whether genesis of non-neuronal cells is altered in $\mathrm{p} 75^{\mathrm{NTR}}$ mutant mice remain to be addressed.
In the present study we tested the hypothesis that $\mathrm{p} 75^{\mathrm{NTR}}$ is expressed by adult dentate gyrus progenitor cells expressing neuronal and/or glial markers and is required for their proliferation and differentiation into neurons, glia and/or other cells types.

\section{Results}

p75 ${ }^{\text {NTR }}$ is present in SGZ progenitor cells

The presence of $\mathrm{p} 75^{\mathrm{NTR}}$ in proliferating cells within the SGZ was assessed by quantitating cells co-expressing BrdU and $\mathrm{p} 75^{\mathrm{NTR}}$. Animals underwent a single injection of BrdU ( $300 \mathrm{mg} / \mathrm{kg}$ body weight) followed by sacrifice 10 h later [25]. SGZ progenitors demonstrate a cell cycle of 14-16 hours [25] and become post-mitotic 3 days after their initial division [26]. As shown in Figure 1, confocal imaging identified SGZ cells expressing both $\mathrm{p} 75^{\mathrm{NTR}}$ and BrdU consistent with $\mathrm{p} 75^{\mathrm{NTR}}$ expression in proliferating progenitor cells. Within these cells, p $75^{\mathrm{NTR}}$ signal was evident in both a nuclear and cytoplasmic distribution (also see Additional file 1). Previous studies applying p $75^{\text {NTR }}$ antibodies for assessment of SVZ progenitors and striatal neurons found either membrane-associated staining or diffuse intracellular staining [21,23,27].

In a second series of studies, animals received a single administration of BrdU at the same dose and were harvested at $2 \mathrm{~h}$ and $2 \mathrm{~d}$ time points. At the first time point, numbers of BrdU-positive cells were relatively low and increased by approximately 3.5 -fold by $2 \mathrm{~d}$ (Figure 2 ). At the first time point essentially all of the BrdU-positive
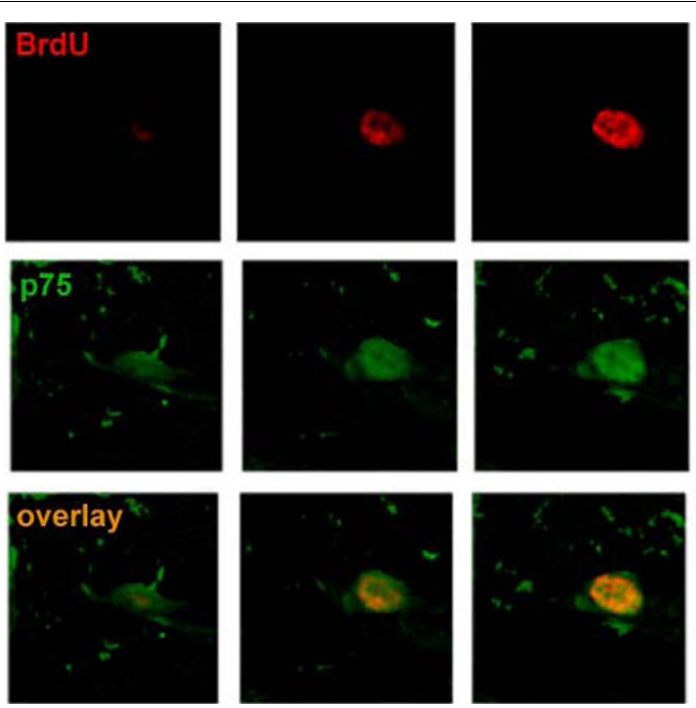
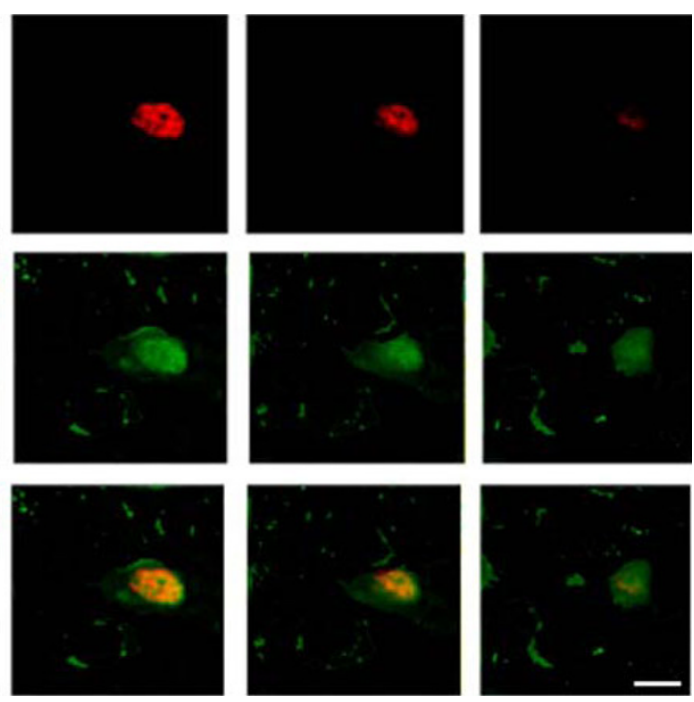

Figure 1 p75 ${ }^{\text {NTR }}$ expression in BrdU-positive SGZ cells, 10 hours post-BrdU injection. Dentate gyrus coronal sections harvested from p75 ${ }^{\mathrm{NTR}}(+/+)$ mice 10 hours after a single BrdU injection were co-immunostained with antibodies against BrdU (red) and p75 ${ }^{\mathrm{NTR}}$ (green). Confocal microscope Z-stacks were collected at $40 \times$ magnification with an interval of $1 \mu$ m between planes with a total of 6 image planes collected from each section. The typical appearance of SGZ fields is shown here. Scale bar (lower right panel): $2 \mu \mathrm{m}$. 


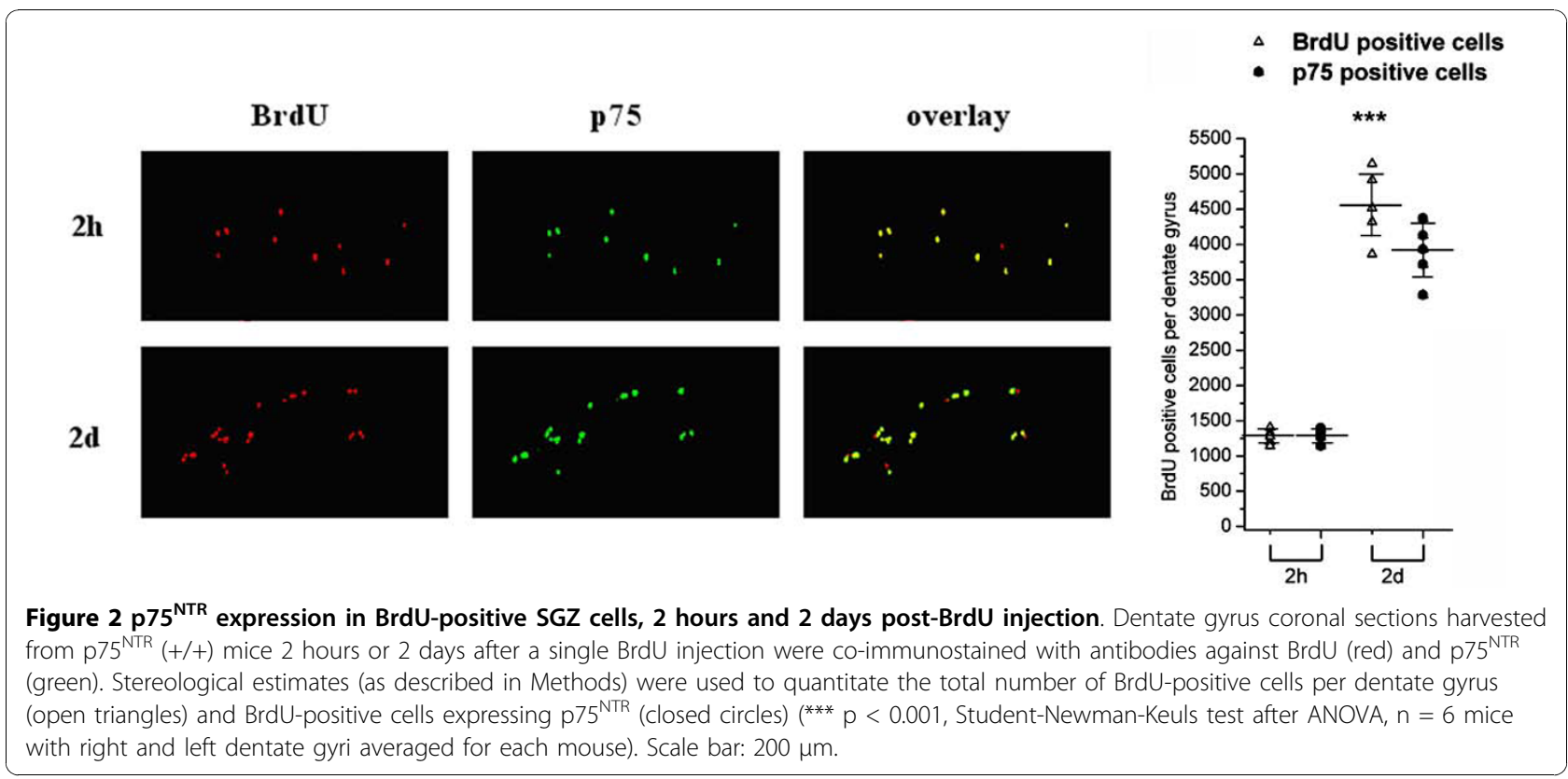

cells expressed $\mathrm{p} 75^{\mathrm{NTR}}$ while at $2 \mathrm{~d}$, some $80 \%$ expressed p $75^{\text {NTR }}$.

\section{Dentate gyrus newborn cells express $\mathrm{p} 75^{\mathrm{NTR}}$ and} neuronal or astrocytic markers $\mathrm{P}^{\mathrm{NTR}}(+/-)$ mice were used to evaluate whether newborn cells in the adult dentate gyrus expressing $\mathrm{p} 75^{\mathrm{NTR}}$ also express neuronal or astrocytic markers. Mice were injected daily for 6 days with BrdU (50 mg/Kg body weight), and the proportions of cells co-expressing BrdU and $\mathrm{p} 75^{\mathrm{NTR}}$ that also expressed NeuN or GFAP were measured (Figures 3 and 4). Following the $6 \mathrm{~d}$ BrdU course, most of the dentate gyrus BrdU-positive cells were found to express $\mathrm{p} 75^{\mathrm{NTR}}$. A large proportion of $\mathrm{BrdU} / \mathrm{p} 75^{\mathrm{NTR}}$-co-expressing cells also labeled with the NeuN neuronal marker (Figure 3D). A smaller
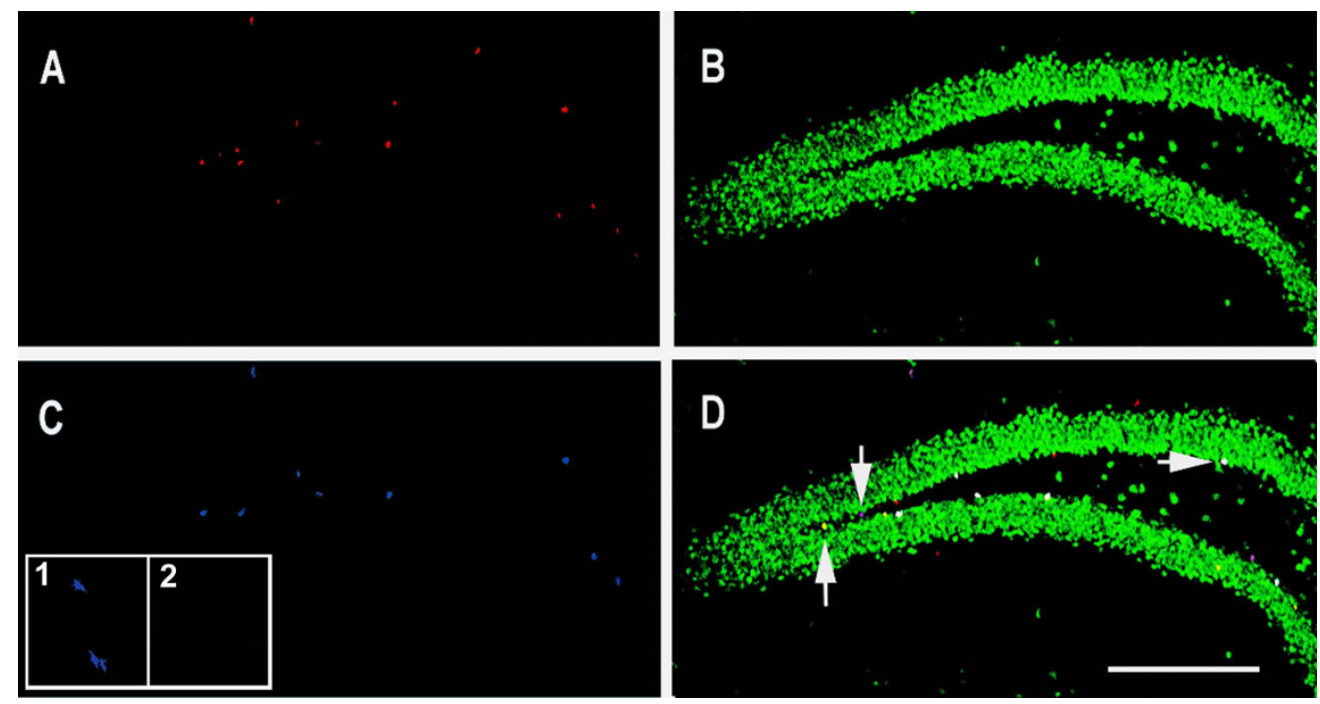

Figure 3 Confocal image analysis of BrdU, NeuN and p75 NTR co-immunostaining. Coronal sections of the dentate gyrus derived from a p75 NTR (+/-) mouse were examined. Tissue was obtained one day following the 6 day BrdU injection protocol. (A) BrdU antibody (red) detects cells primarily located in the SGZ and hilus. (B) NeuN staining (green) demonstrates the characteristic pattern of granule cell layer neurons in the dentate gyrus along with individual cells apparent in the subgranular zone and hilus. (C) p75 NTR staining (blue) identifies cells in the SGZ and hilus. (D) Overlay of images shown in A-C reveals cells co-labeled with BrdU, NeuN and p75 NTR (white, horizontal arrow); BrdU and p75 NTR (pink, up-down arrow); BrdU alone (red); BrdU and NeuN (yellow, down-up arrow). Scale bar: $300 \mu \mathrm{m}$. Inset in figure C: high magnification of p $75^{\mathrm{NTR}}$ staining in $\mathrm{p} 75^{\mathrm{NTR}}(+/+)$ (1) and (-/) (2) mice. 
proportion of $\mathrm{BrdU} / \mathrm{p} 75^{\mathrm{NTR}}$-co-expressing cells were labeled with the GFAP astrocytic marker (Figure 4). As shown in the inset in Figure 3C, immunostaining with $\mathrm{p} 75^{\mathrm{NTR}}$ antibody of sections derived from $\mathrm{p} 75^{\mathrm{NTR}}-/$ mice showed no significant signal and thus verified the specificity of the antibody. These findings suggest that a relatively large proportion of newborn $\mathrm{p} 75^{\mathrm{NTR}}$-positive cells differentiate into neurons with a smaller proportion becoming astrocytes.

\section{Proliferation of dentate gyrus progenitor cells in $\mathrm{p} 75^{\mathrm{NTR}}$} $(+/+)$ and (-/-) mice

To determine whether $\mathrm{p} 75^{\mathrm{NTR}}$ plays in role in dentate gyrus progenitor proliferation and/or differentiation, p75 ${ }^{\mathrm{NTR}}(+/+)$ and $(-/-)$ mice underwent the $6 \mathrm{~d}$ BrdU injection protocol and the above proliferation and differentiation markers were assessed at the 1 day time point. Morphological assessment revealed a decreased number of BrdU-positive cells in p75 ${ }^{\mathrm{NTR}}(-/-)$ mice (Figure 5AE). In (-/-) mice, BrdU-positive cells were more diffusely distributed compared to the aggregates of BrdU-positive cells that are typically seen in p $75^{\text {NTR }}(+/+)$ and other wildtype mice [28,29] (Figure 5F,G). Quantitative stereological analyses (as described in Methods) demonstrated that in $\mathrm{p} 75^{\mathrm{NTR}}(-/-)$ mice the number of BrdU-positive cells was decreased by $59 \%$ ( $\mathrm{p}<0.001)$ relative to control mice (Figure 6A). The lack of any overlap between the values obtained from the $(+/+)(n=9$ mice $)$ and $(-/-)$ ( $n=14$ mice) was consistent with a fully penetrant effect of the mutant genotype and thus further pointed to the significance of the effect of the (-/-) genotype on progenitor proliferation. This decrease in the number of BrdU-positive cells in p $75^{\mathrm{NTR}}(-/-)$ mice was not associated with a decrease in dentate gyrus volume (Figure $6 \mathrm{~B})$, thus consistent with a deceased in progenitor number and density per volume.

\section{Dentate gyrus progenitor differentiation in $\mathrm{p} 75^{\mathrm{NTR}}(+/+)$ and (-/-) mice}

To determine whether the decrease in progenitor proliferation in $\mathrm{p} 75^{\mathrm{NTR}}(-/-)$ dentate gyrus was associated with altered differentiation of progenitors into neurons or glia, sections from the above mice were assessed for co-labeling of BrdU-positive cells with NeuN and GFAP. Confocal microscopic images of cells triple-labeled for BrdU, NeuN and GFAP confirmed the expected presence of newborn cells expressing NeuN or GFAP (Figure $7 \mathrm{~A}-\mathrm{D})$. In $\mathrm{p} 75^{\mathrm{NTR}}(-/-)$ mice, stereological estimates (as described in Methods) (Figure 8A) of BrdU-positive cells revealed a $35 \%$ decrease in the number cells
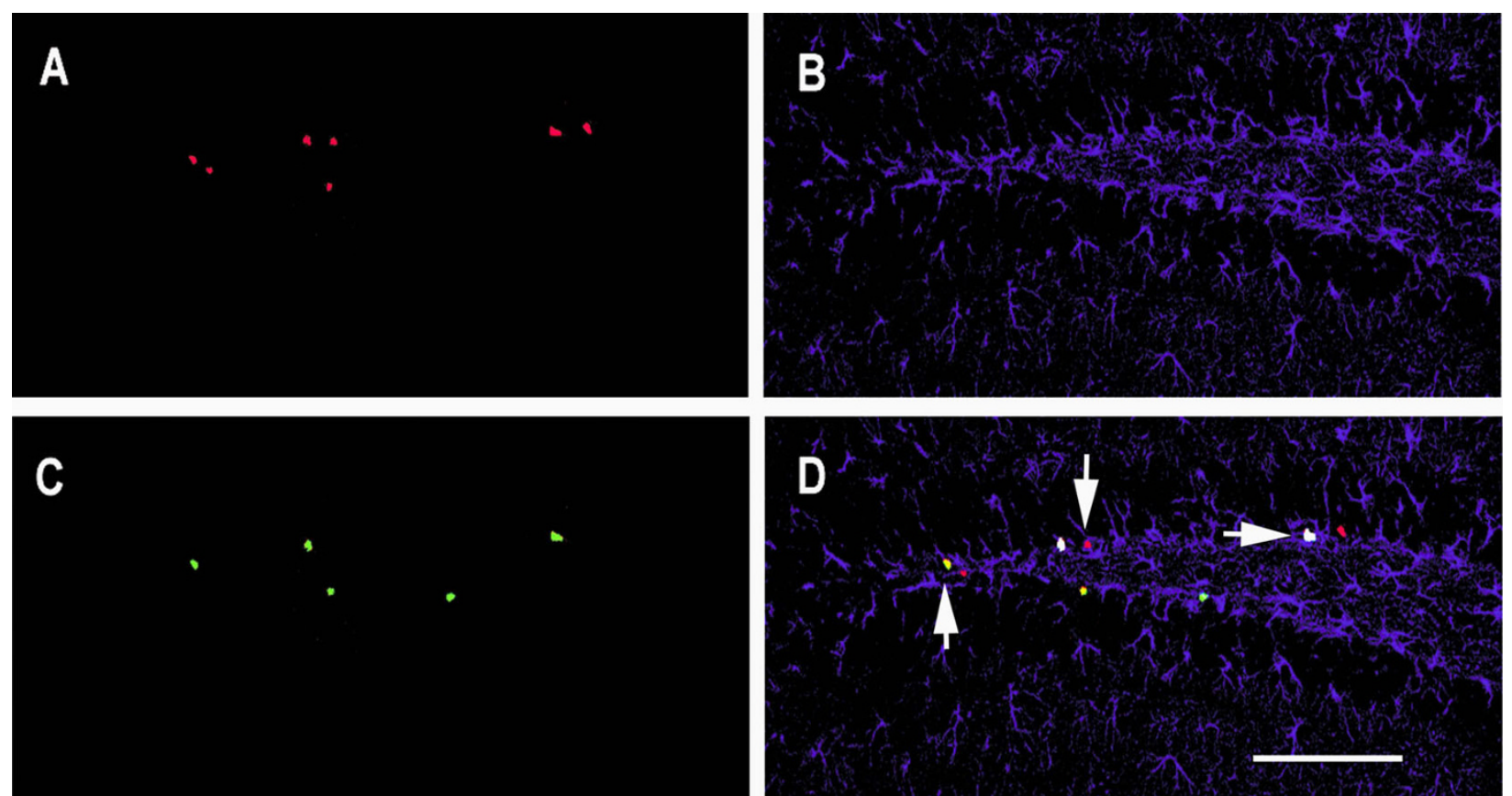

Figure 4 Confocal image analysis of BrdU, GFAP and p $75^{\text {NTR }}$ co-immunostaining. Coronal sections of the dentate gyrus derived from a p75 NTR (+/-) mouse ware examined. Tissue was obtained one day following the 6 day BrdU injection protocol. (A) BrdU antibody (red) detects cells primarily located in the SGZ and hilus. (B) GFAP staining (purple) demonstrates a characteristic fibrillar pattern of astrocytes in the dentate gyrus. (C) p75 NTR staining (green) identifies cells in the SGZ. (D) Overlay of images shown in A-C reveals cells co-labeled with BrdU, GFAP and p75 NTR (white, horizontal arrow); BrdU and p75 NTR (yellow, down-up arrow); BrdU and GFAP (pink, up-down arrow); GFAP and p75 NTR (cyan) and BrdU alone (red). Scale bar: $100 \mu \mathrm{m}$ 


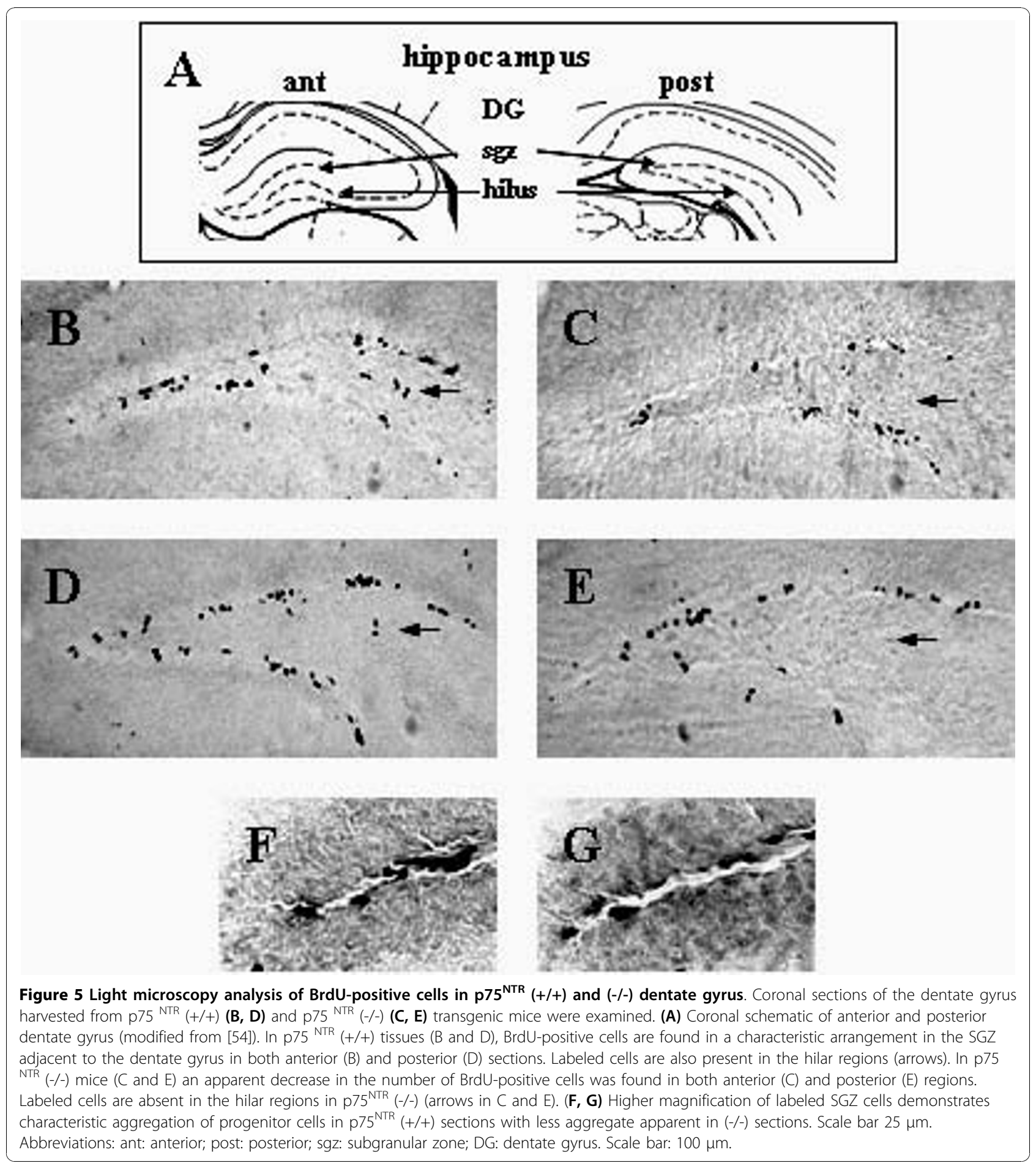

co-expressing NeuN, a $60 \%$ decrease in the number cells co-expressing GFAP and a $64 \%$ decrease in the number of cells expressing neither marker, with the decrease reaching statistical significance for all three categories. Assessment of the proportions of BrdU-positive cells within these three marker categories (Figure 8B) demonstrated that the proportion of BrdU-positive cells co-labeling with NeuN increased from $66 \%$ in $\mathrm{p} 75^{\mathrm{NTR}}$ $(+/+)$ mice to $81 \%$ in $(-/-)$ mice. In contrast, the proportions of BrdU-positive cells co-labeling with GFAP or neither marker decreased in $\mathrm{p} 75^{\mathrm{NTR}}(-/-)$ mice. Thus, in p $75^{\text {NTR }}(-/-)$ mice, dentate gyrus cellular proliferation as indicated by BrdU labeling is considerably decreased (by $59 \%)$ and this decrease includes significantly reduced 

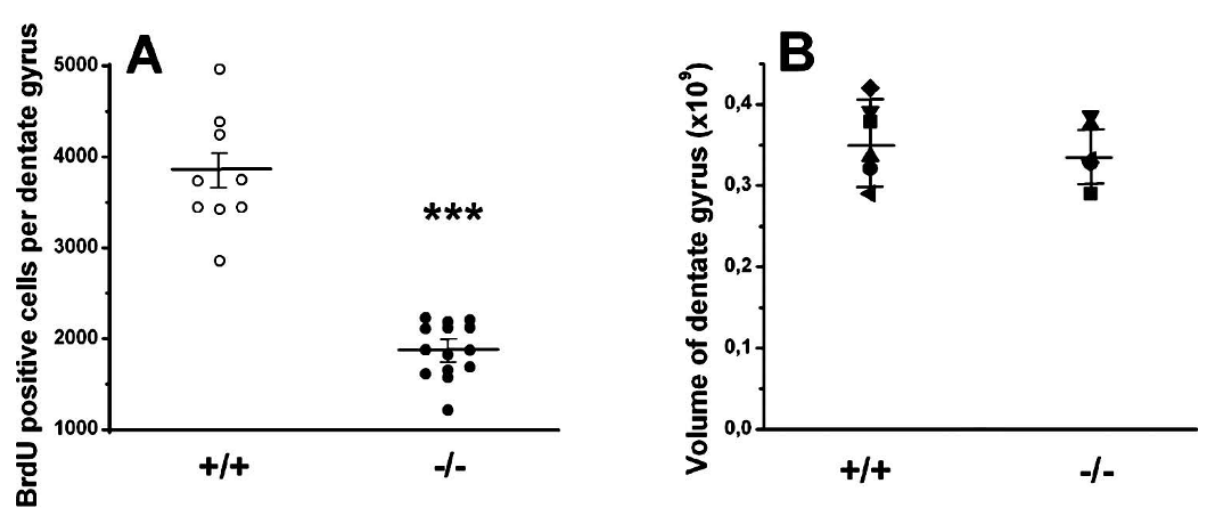

Figure 6 Quantification of BrdU-positive cells in p75 ${ }^{\mathrm{NTR}}(+/+)$ and (-/-) mice. Dentate gyrus volume and numbers of BrdU-positive cells were measured in coronal sections harvested from p75 NTR $(+/+)$ and (-/-) mice. Tissues were obtained one day following the 6-day BrdU injection protocol. (A) Cell counts (as determined by stereological estimates (as described in Methods) in p75 NTR $(-/-)$ mice $(n=14$ mice) were significantly decreased compared to those in $p 75{ }^{\mathrm{NTR}}(+/+)$ mice $(n=9) .{ }^{* *} p<0.001$ between groups, using Student-Newman-Keuls test after ANOVA. For each mouse the cell counts in right and left dentate gyri were averaged. (B) No difference in volume of the granular cell layer was detected between $\mathrm{p} 75^{\mathrm{NTR}}(+/+)$ and (-/-) mice (mean $\pm \mathrm{SE} ; \mathrm{n}=6$ mice per group).
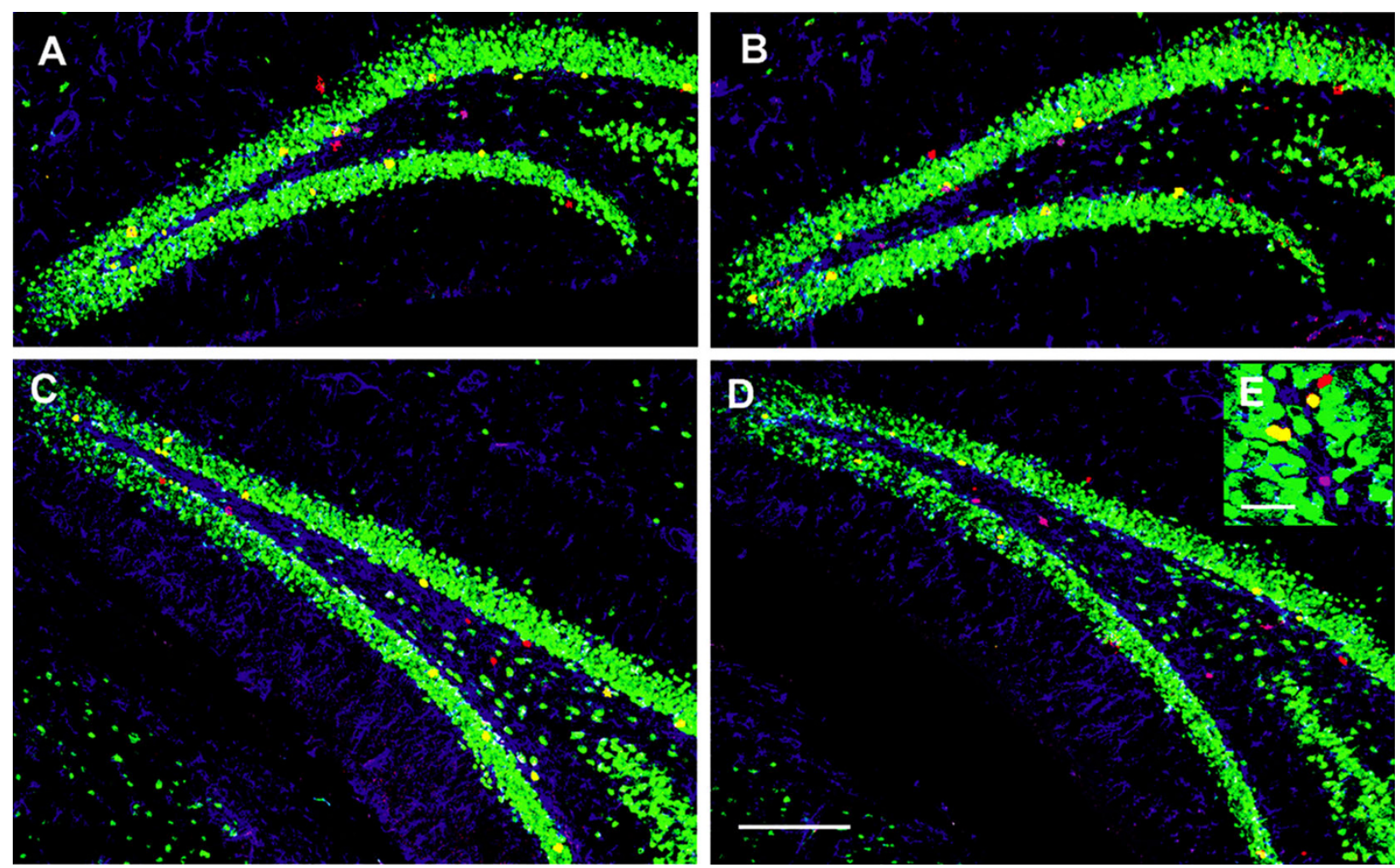

Figure 7 Confocal image analysis of BrdU, NeuN and GFAP co-immunostaining in p75 ${ }^{\mathrm{NTR}}(+/+)$ and (-/-) mice. Coronal sections of the dentate gyrus were co-immunostained with antibodies directed against BrdU (red), NeuN (green) and GFAP (blue). Sections harvested from p75

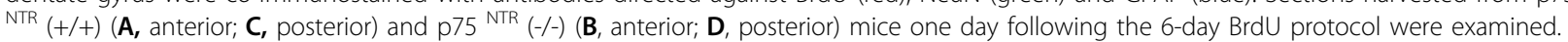
Sections from p75 NTR (-/-) mice (B-D) demonstrate an apparent decrease in the number of SGZ BrdU-positive neurons colocalizing with NeuN marker (yellow) compared to wildtype mice (A-C). (E): Insert: cells staining for BrdU and NeuN (yellow); BrdU and GFAP (pink); BrdU (red); NeuN (green) and GFAP (blue). Scale bar, A-D: $300 \mu \mathrm{m}$ and E: $15 \mu \mathrm{m}$. 


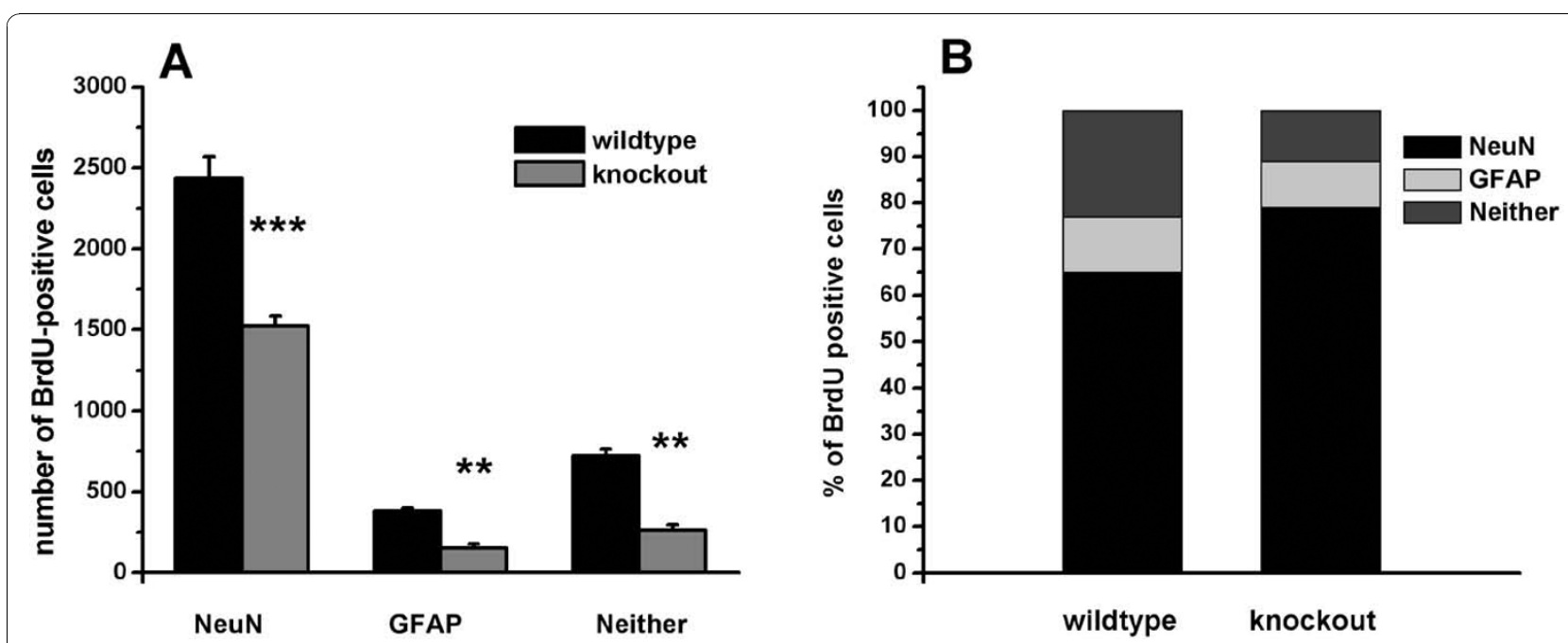

Figure 8 Quantitative analysis of NeuN and GFAP markers expressed by BrdU-positive cells. Coronal sections of the dentate gyrus were co-immunostained with antibodies directed against BrdU, NeuN and GFAP as demonstrated in Figure 7. The numbers of BrdU-positive cells colabeling with NeuN, GFAP or neither marker were determined by stereological estimates (as described in Methods). For each mouse the cell counts in right and left dentate gyri were averaged. (A) A significant decrease in the number of BrdU-positive cells co-expressing NeuN, GFAP and neither marker was found in p75 NTR $(-/-)$ sections. (B) The percentage of BrdU-positive cells expressing NeuN, GFAP and neither marker are indicated. BrdU-positive cells co-labeling with NeuN demonstrated a significant increase from $66 \%$ in p $75^{\mathrm{NTR}}(+/+)$ mice to $81 \%$ in $(-/-)$ mice. ${ }^{* * *}$ $p<0.001$, ** $p<0.01$, between groups, using Student-Newman-Keuls test after ANOVA $(\mathrm{n}=6(+/+)$ and $8(-/-)$ mice).

numbers of cells with neuronal, glial and neither markers. Within this context there is a concomitant modest increase in the proportion of BrdU-positive cells expressing NeuN.

\section{Discussion}

This study demonstrates three key findings relevant to the identification of receptors regulating neurogenesis: first, newborn cells in the adult dentate gyrus, labeling with either neuronal or glial markers, express $\mathrm{p} 75^{\mathrm{NTR}}$ during early stages of proliferation; second, the number of SGZ newborn cells is significantly reduced in $\mathrm{p} 75^{\mathrm{NTR}}$ $(-/-)$ mice; and third, the numbers of cells in all three categories, those expressing neuronal, glial or neither marker, are significantly reduced in $\mathrm{p} 75^{\mathrm{NTR}}(-/-)$ mice.

The $59 \%$ decrease in the number of newborn SGZ cells in $\mathrm{p} 75^{\mathrm{NTR}}(-/-)$ mice found here is similar to the findings of Catts et al.[24], using a 36 hour BrdU oral labeling regime and a 2-week chase period [24], thereby further supporting a role of $\mathrm{p} 75^{\mathrm{NTR}}$ in dentate progenitor proliferation. The prior study also found a $50-60 \%$ reduction in the number of BrdU- NeuN-positive cells at the 2-week time point while the present study detected a $35 \%$ decrease in the number of BrdU- NeuNpositive cells at the 1 day time point following the 6-day BrdU labeling protocol. Hence, our study further supports a role for $\mathrm{p} 75^{\mathrm{NTR}}$ in neurogenesis. This effect could be caused by $\mathrm{p} 75^{\mathrm{NTR}}$ promoting survival and/or differentiation of cells undergoing neuronal differentiation. In contrast to the Catts et al study, we found no decrease in dentate gyrus volume. A lack of effect on dentate volume has also been noted in other studies in which SGZ progenitor proliferation and/or neurogenesis is altered [29-31]. In addition to the difference in time points examined, the prior study applied an oral BrdU dose of $650 \mathrm{mg} / \mathrm{kg} /$ day compared to the present IP dose of $50 \mathrm{mg} / \mathrm{kg} /$ day. While a number of factors are likely to contribute to the difference in findings in terms of dentate volume loss between the studies, it is of interest to note that high BrdU concentrations have been associated with neuronal death [32].

In addition to the effect of $\mathrm{p} 75^{\mathrm{NTR}}$ on neuron formation, a related critical question is its role in the genesis of non-neuronal cells. In the present study, the GFAP glial maker was applied and revealed that in $\mathrm{p} 75^{\mathrm{NTR}}(-/-)$ mice, there were $60 \%$ and $64 \%$ decreases in the total number of newborn cell labeled with GFAP or neither marker, respectively. Thus, in $\mathrm{p} 75^{\mathrm{NTR}}(-/-)$ mice the proportion of newborn cells expressing the NeuN marker is increased while the proportion without this marker is decreased. These studies introduce the important concept that while $\mathrm{p} 75^{\mathrm{NTR}}$ appears to contribute to neurogenesis, it might make an even greater contribution to formation of various populations of non-neuronal cells. Thus p $75^{\text {NTR }}$ cannot be linked specifically to neurogenesis, but instead appears to play a broader role in dentate cell genesis.

The identification of a role for $\mathrm{p} 75^{\mathrm{NTR}}$ in dentate gyrus progenitor cell production is consistent with the emerging picture of $\mathrm{p} 75^{\mathrm{NTR}}$ regulating cell cycle 
mechanisms as well as regulating the proliferation and/ or differentiation of progenitors or embryonic stem cells in cell culture models and in the SVZ in vivo [16-18,22]. These findings are also consistent with other studies in p $75^{\text {NTR }}(-/-)$ mice in which a greater number of sympathetic neurons are present in early development while at later stages a decrease in the number of mature sympathetic neurons was found, suggesting that during development, p $75^{\text {NTR }}$ might first induce proliferation and later apoptosis [12,33,34]. Similarly, during embryonic development, $\mathrm{p} 75^{\mathrm{NTR}}$ appears to participate in the early stages of hippocampal cell proliferation, but at later stages induces death of neurons during maturation $[12,35]$; and finally at the adult stage is expressed at low levels $[11,33,36]$.

While alterations of intrinsic signaling mechanisms in p $75^{\text {NTR }}(-/-)$ progenitors are likely to account for the decrease in neurogenesis observed here, it is also possible that factors extrinsic to progenitor cells contribute. For example, lesions in the entorhinal cortex, hippocampal $\mathrm{CA}_{1}$ and $\mathrm{CA}_{3}$ subregions or dentate gyrus induce an increase in dentate neurogenesis [37-40]. Decreased cholinergic input into the dentate gyrus has also been associated with decreased neurogenesis [41]. Interestingly, the $\mathrm{p} 75^{\mathrm{NTR}}(-/-)$ mice used in the present study and other strains carrying the same mutation were shown to have increased dentate cholinergic innervation $[42,43]$. Thus, the p $75^{\mathrm{NTR}}(-/-)$ mice employed here would be expected to have increased, rather than decreased, neurogenesis if the extrinsic factor of cholinergic innervation played a predominant role.

Studies demonstrating age-related impairments in hippocampal neurogenesis along with recent work showing that brain proNGF levels increase with age [44] raise the possibility that proNGF might contribute to loss of newborn cells through its interaction with p $75^{\mathrm{NTR}}$. Recently developed $\mathrm{p} 75^{\mathrm{NTR}}$ small molecule ligands are able to promote pro-survival signaling and are also able to prevent proNGF-induced death [45]. Findings in the present study will encourage studies to establish whether p $75^{\text {NTR }}$ small molecule ligands can modulate dentate gyrus cell production.

\section{Conclusions}

Our results indicate that $\mathrm{p} 75^{\mathrm{NTR}}$ receptor plays a fundamental role in the generation of dentate newborn cells in the adult brain. Of particular interest are the novel findings that $\mathrm{p} 75^{\mathrm{NTR}}$ is expressed by BrdU-positive cells and that it is also expressed by newborn cells during the time periods in which they express neuronal or glial markers. An additional novel finding is that numbers of newborn neurons, as well as non-neurons, are decreased in $\mathrm{p} 75^{\mathrm{NTR}}(-/-)$ mice pointing to a role for this receptor in the formation of neurons as well as non-neurons.
These results provide a basis for examining the effects of recently developed $\mathrm{p} 75^{\mathrm{NTR}}$ small molecule ligands in dentate cell formation.

\section{Methods}

Animals

Animal studies were performed according to National Institutes of Health guidelines under an approved local protocol from the San Francisco VA Medical Center. Two sets of animals were used. Balb/c wildtype mice, and mice carrying a mutation in exon 3 of the p $75^{\text {NTR }}$ gene [46], both purchased from the Jackson laboratory (Bar Harbor, ME). These mutant mice were created using 129 strain ES cells with subsequent breeding in a mixed 129/Balb/c background. Mutant mice were maintained in our colony via successive Balb/c backcrosses. Mice used in the present study were derived via a minimum of 6-8 Balb/c backcrosses resulting in estimated congenic Balb/c homogeneity of 97-99\% [47]. Genotyping was conducted using RT-PCR as previously described [42]. p75 NTR $(+/-)$ littermate crosses were used to generate $\mathrm{p} 75^{\mathrm{NTR}}(+/+)$ and $(-/-)$ littermates. All studies were limited to littermate comparisons and mice were studied at 3 months of age unless otherwise indicated. In each genotype group, approximately equivalent numbers of male and female mice were included. Animals were housed in standard conditions with four or five mice per cage.

\section{BrdU injections and tissue preparation}

Bromodeoxyuridine (BrdU; Sigma, St. Louis, MO) was dissolved in sterile $0.9 \% \mathrm{NaCl}$ and filtered. Mice received i.p. injections using the dosages and schedules described in Results. Animals underwent transcardial perfusion with $4 \%$ paraformaldehyde in phosphate buffer. Brains were harvested, stored in fixative overnight, transferred into $30 \%$ sucrose and stored overnight at $4^{\circ} \mathrm{C}$. Coronal sections $(50 \mu \mathrm{m}$ thick) were cut on a sliding freezer microtome and stored at $4^{\circ} \mathrm{C}$ in $0.1 \mathrm{M}$ phosphate buffer containing $0.005 \%$ azide. In order to denature DNA for BrdU immunohistochemistry, free-floating sections were incubated in $50 \%$ formamide/50\% $2 \times \mathrm{SSC}(0.3 \mathrm{M} \mathrm{NaCl} /$ $0.03 \mathrm{M}$ sodium citrate) at $37^{\circ} \mathrm{C}$ for 2 hours, washed in 2 $\times \mathrm{SSC}$, incubated in $2 \mathrm{~N} \mathrm{HCl}$ for 30 minutes at $37^{\circ} \mathrm{C}$ and rinsed in $0.1 \mathrm{M}$ borate buffer ( $\mathrm{pH} \mathrm{8.5)}$ ) for 15 minutes.

\section{Immunohistochemistry}

Sections were treated with $0.6 \% \mathrm{H}_{2} \mathrm{O}_{2}$ to block endogenous peroxides, rinsed in phosphate buffer $2 \times 10 \mathrm{~min}$ and then incubated in blocking solution $(0.1 \mathrm{M}$ phosphate buffer, $0.1 \%$ triton $\mathrm{X}-100,2 \%$ normal serum and BSA $1 \mathrm{~g} / \mathrm{l}$ ) for $1 \mathrm{~h}$. Sections were then incubated with mouse monoclonal BrdU antibody (Boehringer Mannheim, Indianapolis, Indiana; $1: 400)$ overnight at $4^{\circ} \mathrm{C}$ 
followed by incubation with biotinylated sheep antimouse IgG secondary antibody (1:200; Amersham, Piscataway, New Jersey) for $1 \mathrm{~h}$. ABC reagent $(50 \mu \mathrm{l} / 5$ $\mathrm{ml}$; Vectastain Elite, Vector Laboratories, Burlingame, California;) was applied for $2 \mathrm{~h}$. Diaminobenzidine (FastDAB; Sigma) was used as chromogen. Stained cells were visualized under light microscopy using differential interference contrast (Zeiss Axoplan 2). Images were acquired using a Pixera digital camera and processed with Adobe Photoshop 5.5. Only general contrast enhancements and color level adjustments were carried out; images were not otherwise digitally modified.

\section{Immunofluorescence}

After pretreatment for BrdU, sections were kept in blocking solution for $2 \mathrm{~h}$. They were then incubated for $24 \mathrm{~h}$ at $4^{\circ} \mathrm{C}$ with primary antibodies diluted in $0.1 \mathrm{M}$ TBS containing $0.1 \%$ triton and $5 \%$ donkey serum (TBS-T). Antibodies were directed against the following antigens: BrdU (rat monoclonal, 1:500; Accurate Scientific, Westbury, New York); p75 ${ }^{\text {NTR }}$ extracellular domain (rabbit monoclonal, cat\# 05-446, lot\# 22972, 1:400; Chemicon, Temeluca, California, now a part of Millipore, Massachusetts), NeuN (mouse monoclonal, 1:800; Chemicon) and GFAP (rabbit polyclonal, Dako, 1:1000; Glostrup, Denmark, and mouse monoclonal, Boehringer Mannheim, 1:1000, Indianapolis, USA). Secondary antibodies raised in donkey (Cy3 for detecting BrdU; FICT for $\mathrm{p} 75^{\mathrm{NTR}}$ or NeuN, and Cy 5 for GFAP or $\mathrm{p} 75^{\mathrm{NTR}}$; all from Jackson ImmunoResearch; West Grove, Pennsylvania; $6 \mu \mathrm{g} / \mathrm{ml}$ ) were applied for $2 \mathrm{~h}$ at room temperature. Sections were washed, mounted, and coversliped in mounting medium for fluorescence (Vectashield, Vector Laboratories, Burlingame, California). Fluorescent signal was detected using a confocal microscope (Leica Laser Confocal TCS SP) and the images were processed with Adobe Photoshop. Only general contrast enhancements and color level adjustments were carried out; images were not otherwise digitally modified.

\section{Quantification of BrdU-labeled cells}

Under light microscopy (using mercury lamp settings on the Leica Laser Confocal TCS SP microscope), numbers of DAB-stained cells within the subgranular layer located within one cell diameter of the granule cell layer boundary were determined using the optical disector principle in which the uppermost focal plane of each section was not counted $[48,49]$. The number of DABstained cells in the subgranular zone was counted in every fourth section within a series of $50 \mu \mathrm{m}$ coronal sections extending throughout the rostra-caudal axis of the granular cell layer. Cell counts were restricted to the top $15 \mu \mathrm{m}$ of each section where immunostaining was optimal (see below). The first section to be counted was randomly selected out of the first four cut sections and 7-9 sections were assessed in order to span each dentate gyrus. The disector height was set at $6 \mu \mathrm{m}$ [50] and from each section, 7-8 z-planes were assessed to count BrdU-positive cells. The estimated final mounted section mean thickness was $36.46 \mu \mathrm{m}$ (consistent with post mounting dehydration); with a coefficient of variation of 0.041 . Guard zones (distance between the section surface and the optical disector) were $4 \mu \mathrm{m}$ on top and bottom sides. For each section, the entire dentate gyrus area was used to evaluate the BrdU-positive cells, thus no sampling was applied. For performing cell counts with either DAB or fluorescent staining, a 40x, PlanApochromat, NA: 1.25, oil immersion objective was applied. BrdU-positive cells were also present in the hilar area (arrows in Figure 5B-E), but these cells were not counted since they likely represent endothelial and other non-neuronal cells $[28,29]$.

\section{Quantification of granular cell reference volume}

Granular cell reference volumes were estimated using previously established protocols and Cavalieri's direct estimator [48,49,51]. Serial coronal sections were imaged using the Leica TCS-SP confocal microscope with a multiband confocal imaging spectrophotometer. For each section, the GCL area was outlined using $20 \times$ objective images (20x, Plan-Apochromat, NA: 0.7, multiple immersion) and analyzed with Scion Beta 4.0.2 (NIH) software. GCL total volume was calculated from $\mathrm{V}=\Sigma \mathrm{A} \times \mathrm{T} \times 4$ where $\Sigma \mathrm{A}$ is the sum of area measurements, $\mathrm{T}$ is the section thickness $(50 \mu \mathrm{m})$ and 4 is the periodicity of the section sample. For volume determination, the coefficient of error was calculated to be 0.04 (the standard deviation of section area values divided by the square root of the estimated mean, Glaser and Wilson [52]). For volume studies, 6 animals from each genotype group were randomly selected, right and left dentate gyri were measured and for each mouse the two values were averaged.

\section{Colocalization of BrdU and cell phenotype markers}

Colocalization analysis was performed using the Leica Laser Confocal TCS SP microscope. Sections were optically sliced in the Z-axis at $4 \mu \mathrm{m}$ intervals and fluorescent images were acquired, one per each marker. In early studies, we determined that immunostaining signal was robust without an observable decline through Zaxis distances of approximately $20 \mu \mathrm{m}$ from the section surface and thereafter began to decrease. Therefore, analysis was restricted to the top $15 \mu \mathrm{m}$ of each section where immunostaining was optimal. In each section the number of BrdU-positive cells associated with markers for NeuN or GFAP was counted as described by Peterson [53]. For each dentate gyrus, 7-9 sections were 
assessed (the number required to fully span each dentate gyrus) and each BrdU-positive cell were assessed for phenotype markers. For each mouse, data from the right and left gyri were averaged. The proportions of BrdUpositive cells associated with NeuN and GFAP markers were calculated. Images obtained from individual optical slices were imported to Adobe Photoshop 5.5 for composition of figures.

\section{Statistics analysis}

The data are expressed as mean values \pm standard error of mean (SEM) from $n$ independent experiments. Statistical analyses were performed using one-way analysis of variance (ANOVA) with number of positive cells as a factor, followed by Student-Newman-Keuls post hoc comparisons or Student's t test, when required.

\section{Additional material}

Additional file 1: Confocal 3D reconstructed imaging of $\mathrm{p} 75^{\mathrm{NTR}}$ expression in BrdU-positive granular cells. Dentate gyrus coronal sections harvested from three $\mathrm{p} 75^{\mathrm{NTR}}+/+$ mice were co-immunostained with antibodies against p75 ${ }^{\text {NTR }}$ (green) and BrdU (red). A representative confocal 3D-reconstructed, merged image of a SGZ cell demonstrates nuclear BrdU signal with p $75^{\mathrm{NTR}}$ signal evident in cytoplasmic and nuclear areas. Orthogonal images demonstrate $\mathrm{x}-\mathrm{z}$ (top) and $\mathrm{y}-\mathrm{z}$ (right) planes. Scale bar: $5 \mu \mathrm{m}$.

\section{Acknowledgements}

Supported by a PEW Fellowship in Biomedical Science and Fundacion Antorchas (RB) and NIA R01 AG09873 (FL).

\section{Author details}

'Department of Neurology, UCSFNAMC, San Francisco, CA, 94121, USA. ${ }^{2}$ Institute of Cell Biology and Department of Physiology, University of Buenos Aires, Buenos Aires, Argentina. ${ }^{3}$ Department of Neurology and Neurological Sciences, Stanford University, Palo Alto, CA, 94035, USA.

\section{Authors' contributions}

$\mathrm{RB}$ and $\mathrm{FL}$ each contributed to the conceptualization, design, execution and analysis of these studies. Both contributed to the manuscript preparation.

Received: 10 March 2010 Accepted: 20 October 2010

Published: 20 October 2010

\section{References}

1. McKay R: Stem cells in the central nervous system. Science 1997, 276:66-71.

2. Temple S, Alvarez-Buylla A: Stem cells in the adult mammalian central nervous system. Curr Opin Neurobiol 1999, 9:135-141.

3. Emsley JG, Mitchell BD, Kempermann G, Macklis JD: Adult neurogenesis and repair of the adult CNS with neural progenitors, precursors, and stem cells. Prog Neurobiol 2005, 75:321-41.

4. Christie BR, Cameron HA: Neurogenesis in the adult hippocampus. Hippocampus 2006, 16:199-207.

5. Hagg T: Endogenous regulators of adult CNS neurogenesis. Curr Pharm Des 2007, 13:1829-40.

6. Gould E: How widespread is adult neurogenesis in mammals? Nat Rev Neurosci 2007, 8:481-8.
7. Horner PJ, Gage FH: Regenerating the damaged central nervous system. Nature 2000, 407:963-969.

8. Picard-Riera N, Nait-Oumesmar B, Baron-Van Evercooren A: Endogenous adult neural stem cells: limits and potential to repair the injured central nervous system. J Neurosci Res 2004, 76:223-31.

9. Huang EJ, Reichardt LF: TRK receptors: roles in neuronal signal transduction. Annual Review of Biochemistry 2003, 72:609-642.

10. Hempstead BL: The many faces of p75. Curr Op Neurobiol 2002, 12:260-267.

11. Chao MV: Neurotrophins and their receptors: a convergence point for many signalling pathways. Nat Rev Neurosci 2003, 4:299-309.

12. Gentry JJ, Barker PA, Carter BD: The p75 neurotrophin receptor: multiple interactions and numerous functions. Prog Brain Res 2004, 146:25-39.

13. Nakamura T, Endo Kl, Kinoshita S: Identification of human oral keratinocyte stem/progenitor cells by neurotrophin receptor p75 and the role of neurotrophin/p75 signaling. Stem Cells 2007, 25:628-638.

14. Seidel K, Erck C, Buchberger A: Evidence for the participation of nerve growth factor and its low-affinity receptor $\left(\mathrm{p} 75^{\mathrm{NTR}}\right)$ in the regulation of the myogenic program. J Cellular Physiol 1998, 176:10-21.

15. Chittka A, Arevalo JC, Rodriguez-Guzman M, Pérez P, Chao MV, Sendtner M: The $\mathrm{p} 75^{\mathrm{NTR}}$-interacting protein $\mathrm{SC} 1$ inhibits cell cycle progression by transcriptional repression of cyclin. E J Cell Biol 2004, 164:985-96.

16. Lachyankar MB, Condon PJ, Daou MC, De AK, Levine JB, Obermeier A Ross AH: Novel functional interactions between Trk kinase and p75 neurotrophin receptor in neuroblastoma cells. J Neurosci Res 2003, 71:157-72.

17. Cattaneo E, McKay RP: Proliferation and differentiation of neuronal stem cells regulated by nerve growth factor. Nature 1990, 347:762-765.

18. Hosomi S, Yamashita T, Aoki M, Tohyama M: The p75 receptor is required for BDNF-induced differentiation of neural precursor cells. Biochem Biophy Res Comm 2003, 301:1011-1015.

19. Gascon E, Vutskits L, Zhang H, Barral-Moran MJ, Kiss PJ, Mas C, Kiss JZ: Sequential activation of p75 and TrkB is involved in dendritic development of subventricular zone-derived neuronal progenitors in vitro. Eur J Neurosci 2005, 21:69-80.

20. Moscatelli I, Pierantozzi E, Camaioni A, Siracusa G, Campagnolo L: p75 neurotrophin receptor is involved in proliferation of undifferentiated mouse embryonic stem cells. Exp Cell Res 2009, 315:3220-32.

21. Giuliani A, D'Intino G, Paradisi M, Giardino L, Calza L: p75 ${ }^{\text {NTR }}$ Immunoreactivity in the subventricular zone of adult male rats: expression by cycling cells. J Mol Hist 2004, 35:749-758.

22. Gascon E, Vutskits L, Jenny B, Durbec P, Kiss JZ: PSA-NCAM in postnatally generated immature neurons of the olfactory bulb: a crucial role in regulating p75 expression and cell survival. Development 2007, 134:1181-1190.

23. Young KM, Merson TD, Sotthibundhu A, Coulson EJ, Bartlett PF: p75 neurotrophin receptor expression defines a population of BDNFresponsive neurogenic precursor cells. J Neurosci 2007, 27:5146-55

24. Catts VS, Al-Menhali N, Burne TH, Colditz MJ, Coulson EJ: The p75 neurotrophin receptor regulates hippocampal neurogenesis and related behaviours. Eur J Neurosci 2008, 28:883-92.

25. Hayes NL, Nowakowski RS: Dynamics of cell proliferation in the adult dentate gyrus of two inbred strains of mice. Dev Brain Res 2002, 134:77-85.

26. Kempermann G, Jessberger S, Steiner B, Kronenberg G: Milestones of neuronal development in the adult hippocampus. Trends Neurosci 2004, 27:447-52.

27. Hanbury R, Charles V, Chen EY, Leventhal L, Rosenstein JM, Mufson EJ, Kordower $\mathrm{JH}$ : Excitotoxic and metabolic damage to the rodent striatum: role of the P75 neurotrophin receptor and glial progenitors. J Comp Neurol 2002, 444:291-305.

28. Kempermann G, Kuhn GF, Gage FH: More hippocampal neurons in adult mice living in an enriched environment. Nature 1997, 386:493-495.

29. Van Praag H, Kempermann G, Gage FH: Running increases cell proliferation and neurogenesis in the adult mouse dentate gyrus. Nat Neurosci 1999, 2:266-270.

30. Kempermann G, Gage FH: Experience-dependent regulation of adult hippocampal neurogenesis: effects of long-term stimulation and stimulus withdrawal. Hippocampus 1999, 9:321-32. 
31. Kempermann G, Kuhn HG, Gage FH: Experience-induced neurogenesis in the senescent dentate gyrus. J Neurosci 1998, 18:3206-12.

32. Kolb B, Pedersen B, Ballermann M, Gibb R, Whishaw IQ: Embryonic and Postnatal Injections of Bromodeoxyuridine Produce Age-Dependent Morphological and Behavioral Abnormalities. J Neuroscie 1999, 19:2337-2346

33. Lee $T$, Kato $H$, Pan L, Ryu JH, Kogure K, Itoyama Y: Localization of nerve growth factor, trkA and p75 immunoreactivity in the hippocampal formation and basal forebrain of adult rats. Neuroscience 1998 , 83:335-349.

34. Nykjaer A, Willnow TE, Petersen CM: p75 ${ }^{\mathrm{NTR}}$ - live or let die. Curr Op Neurobiol 2005, 15:49-57.

35. Kalb R: The protean actions of neurotrophins and their receptors on the life and death of neurons. Trends in Neurosci 2005, 28:5-11.

36. Dougherty KD, Milner TA: p75 immunoreactivity in the rat dentate gyrus is mostly within presynaptic profiles but is also found in some astrocytic and postsynaptic profiles. J Comp Neurol 1999, 407:77-91.

37. Gould $E$, Tanapat $P$ : Lesion-induced proliferation of neuronal progenitors in the dentate gyrus of the adult rat. Neuroscience 1997, 80:427-436

38. Bengzon J, Kakaia Z, Elmer E, Nanobashvili A, Kokaia M, Lindvall O: Apoptosis and proliferation of dentate gyrus neurons after single and intermittent limbic seizures. Proc Natl Acad Sci USA 1997, 94:10432-10437.

39. Cameron HA, McEwen BS, Gould E: Regulation of adult neurogenesis by excitatory input and NMDA receptor activation in the dentate gyrus. $J$ Neurosci 1995, 15:4687-4692.

40. Bernabeu R, Sharp FR: NMDA and AMPA/kainate glutamate receptors modulate dentate neurogenesis and CA3 synapsin-I in normal and ischemic hippocampus. J Cereb Blood Flow Metab 2000, 20:1669-80.

41. Cooper-Khun CM, Winkler J, Khun HG: Decreased neurogenesis after cholinergic forebrain lesion in the adult rat. J Neurosci Res 2004 77:155-165.

42. Yeo TT, Chua-Couzens J, Butcher LL, Bredesen DE, Cooper JD, Valletta JS, Mobley WC, Longo FM: Absence of p75 causes increased basal forebrain cholinergic neuron size, choline acetyltransferase activity, and target innervation. J Neuroscie 1997, 15:7594-7605.

43. Van Lieshout EM, Van Der Heijden I, Hendriks WJ, Van Der Zee CE: A decrease in size and number of basal forebrain cholinergic neurons is paralleled by diminished hippocampal cholinergic innervation in mice lacking leukocyte common antigen-related protein tyrosine phosphatase activity. Neuroscience 2001, 102:833-841.

44. Al-Shawi R, Hafner A, Chun S, Raza S, Crutcher K, Thrasivoulou C, Simons P, Cowen T: ProNGF, sortilin, and age-related neurodegeneration. Ann N Y Acad Sci 2007, 1119:208-15.

45. Massa SM, Xie Y, Yang T, Harrington AW, Kim ML, Yoon SO, Kraemer R, Moore LA, Hempstead BL, Longo FM: Small, nonpeptide p $75^{\text {NTR }}$ ligands induce survival signaling and inhibit proNGF-induced death. J Neurosci 2006, 26:5288-300.

46. Lee KF, Li E, Huber LJ, Landis SC, Sharpe AH, Chao MV, Jaenisch R: Targeted mutation of the gene encoding the low affinity NGF receptor p75 leads to deficits in the peripheral sensory nervous system. Cell 1992, 69:737-49.

47. Silver LM: Laboratory mice. Mouse genetics. Concepts and applications Oxford: Oxford University Press; 1995, 32-61.

48. Gundersen HJ, Bagger P, Bendtsen TF, Evans SM, Korbo L, Marcussen N, Moller A, Nielsen K, Nyengaard JR, Pakkenberg B, et al: The new stereological tools: disector, fractionator, nucleator and point sampled intercepts and their use in pathological research and diagnosis. Acta Pathol Microbiol Immunol Scand 1988, 96:857-881.

49. Cogesshal RE, Lekan HA: Methods for determining numbers of cells and synapses: a case for more uniform standards of review. J Comp Neurol 1996, 364:6-15

50. Keuker Jl, Vollmann-Honsdorf GK, Fuchs E: How to use the optical fractionator: an example based on the estimation of neurons in the hippocampal CA1 and CA3 regions of tree shrews. Brain Research Protocols 2001, 7:211-221.

51. O'Kusky JR, Ye P, D'Ercole JD: Insulin-like growth factor-I promotes neurogenesis and synaptogenesis in the hippocampal dentate gyrus during postnatal development. J Neurosci 2000, 20:8435-8442.

52. Glaser EM, Wilson PD: The coefficient of error of optical fractionator population size estimates: a computer simulation comparing three estimators. J Microsc 1998, 192:163-171.
53. Peterson DA, Leppert JT, Lee K, Gage FH: Basal forebrain neuronal loss in mice lacking neurotrophin receptor p75. Science 1997, 277:837-838.

54. Franklin K, Paxinos G: The Mouse Brain in Stereotaxic Coordinates. Academic Press, San Diego; 1997.

doi:10.1186/1471-2202-11-136

Cite this article as: Bernabeu and Longo: The p75 neurotrophin receptor is expressed by adult mouse dentate progenitor cells and regulates neuronal and non-neuronal cell genesis. BMC Neuroscience 2010 11:136.

\section{Submit your next manuscript to BioMed Central and take full advantage of:}

- Convenient online submission

- Thorough peer review

- No space constraints or color figure charges

- Immediate publication on acceptance

- Inclusion in PubMed, CAS, Scopus and Google Scholar

- Research which is freely available for redistribution

Submit your manuscript at www.biomedcentral.com/submit
C) Biomed Central 